\title{
FINITE ELEMENT ANALYSIS OF AIRFIELD FLEXIBLE PAVEMENT
}

\author{
G. LEONARDI ${ }^{1}$
}

\begin{abstract}
The paper presents a numerical study of an aircraft wheel impacting on a flexible landing surface. The proposed 3D model simulates the behaviour of flexible runway pavement during the landing phase. This model was implemented in a finite element code in order to investigate the impact of repeated cycles of loads on pavement response.

In the model, a multi-layer pavement structure was considered. In addition, the asphalt layer (HMA) was assumed to follow a viscoelastoplastic behaviour.

The results demonstrate the capability of the model in predicting the permanent deformation distribution in the asphalt layer.
\end{abstract}

Key words: Impact; FEM; airfield pavement; aircraft landing, Abaqus, flexible pavement

\section{INTRODUCTION}

In recent years, several studies analyse the behaviour of flexible pavements developing $3 \mathrm{D}$ finite element models that are capable to determine accurately stresses and deformations in pavements caused by the aircraft with multiple-wheel landing gear configuration.

Flexible pavement can often be idealized as a closed system consisting of several linear elastic layers, with each layer both uniform in thickness and infinite in horizontal extent. This simplified approach to pavement modelling is no longer acceptable [1-4]. Differently from the layered theory, the FE method can be a complex and costly analysis tool; it is thus employed only when accurate results are needed. Although involving a more complicated formulation than the multi-layer elastic theory, the application of FE techniques is generally thought to allow an accurate simulation of pavement problems. Furthermore, this method allows to consider almost all controlling parameters (e.g. dynamic loading, discontinuities such as cracks and shoulder joints, viscoelastic and nonlinear elastic behaviour, infinite and stiff foundations, system damping, quasi-static analysis, crack propagation) Al-Quadi et al. [5].

1 Department of Civil, Energy, Environmental and Materials Engineering (DICEAM), University of Reggio Calabria, 89060, Reggio Calabria, Italy, e-mail: giovanni.leonardi@unirc.it 
For example, the model used in the study conducted by Zaghloul and White [6] employed 3D dynamic finite element to investigate the response of moving loads on pavement structures. Zaghloul employed a visco-elastic model for the asphalt concrete, an extended Drucker-Prager model for granular base course and Calm Clay model for the clay subgrade soils Zaghloul [7].

Taciroglu [8] simulated the pavement responses using three-dimensional finite element analysis and adopted the K- $\theta$ model and the Uzan model as the nonlinear unbound granular material model and linear subgrade soils model.

Kim [9] found that nonlinearity of unbound layers using the Drucker-Prager plasticity model was not suitable for pavement analyses. Therefore, the Uzan model was adopted for granular materials and cohesive soils for the nonlinear analysis. Mohr-Coulomb failure criterion was employed in the nonlinear finite element analysis.

Erlingsson [10] conducted three-dimensional finite element analyses of a heavy vehicle simulator used to test low volume road structures. A linear elastic material model was used and the single and dual wheel configurations were given.

More recently, the theory of viscoelastoplasticity has also been extensively used to analyse HMA materials. Chehab [11] developed an advanced material characterization procedure including the theoretical models and its supporting experimental testing protocols necessary for predicting the response of asphaltic mixtures subjected to tension loading. The model encompasses the elastic, viscoelastic, plastic and visco-plastic components of asphalt concrete behaviour.

Pirabarooban et al. [12] successfully developed a viscoelastoplastic creep model representing the time-dependency of asphalt mixtures to evaluate their rutting potential and to identify factors having a significant effect. The creep model parameters were derived from Asphalt Pavement Analyzer test results.

In recent years, researchers have successfully applied linear viscoelastic theory to describe the behaviour of HMA materials. Elseifi et al. [13] conducted a comparative study between the elastic FE model and the linear viscoelastic FE model, and concluded that it is imperative to incorporate a viscoelastic constitutive model into pavement design methods for improved accuracy. Yin et al. [14] showed that 3-D finite element modelling utilizing viscoelastic material properties provides reasonable prediction of strain response in the field.

Onyango [15] evaluated existing mechanistic models that predict permanent deformation (rutting) in asphalt mixes by comparing computed permanent deformation to that measured in a full-scale accelerated pavement test.

The aim of this study is to assess the effects of repeated heavy impacts caused by aircraft landing gear wheels on a flexible airport pavement. In particular, the paper implemented a 3-D FE model to simulate the pavement performance under aircraft landing in order to investigate the relationship between the rutting depth and the number of loads. 


\section{Materials AND Methods}

\subsection{PAVEMENT MODEL}

Flexible pavements can often be idealized as closed systems consisting of several layers; so it was decided to model the surface, base, sub-base, and sub-grade material using three dimensional finite elements.

The pavement structure in the application is based on the structure as found for the runway of the Reggio Calabria (Italy) airport, and it consists of a $100 \mathrm{~mm}$ thick asphalt concrete layer as the surfacing course, a $150 \mathrm{~mm}$ thick of bitumen-treated mixture as the base course, a $210 \mathrm{~mm}$ thick granular layer as the sub-base course and a compacted soil subgrade (Figure 4).

\subsection{Contact AREA AND ASSOCIATED STRESS}

The most common way of applying wheel loads in a finite element analysis is to apply pressure loads to a circular or rectangular equivalent contact area with uniform tire pressure Huang [16]. The contact area can be calculated as:

$$
A_{c}=\frac{P}{p}
$$

where $P$ is the wheel load and $p$ is the tire pressure. In the model the Airbus 321 tires were considered [17].

Table 1.

A321 Characteristics.

\begin{tabular}{|c|c|}
\hline Maximum ramp weight & $\mathbf{8 3 4 0 0} \mathbf{~ k g}$ \\
\hline Percentage of weight on main gear group & $95.4 \%$ \\
\hline Nose gear tire size & $30 \times 8.8 \mathrm{R} 15$ \\
\hline Nose gear tire pressure & $10.8 \mathrm{bar}$ \\
\hline Main gear tire size & $1270 \times 455 \mathrm{R} 22$ \\
\hline Main gear tire pressure & $13.6 \mathrm{bar}$ \\
\hline
\end{tabular}

In the finite element model, the contact area $\mathrm{A}_{\mathrm{c}}$ was represented as a rectangle having a length $\mathrm{L}_{\text {and }}$ a width $\mathrm{L}^{\prime}=0.7 \cdot \mathrm{L}$. To evaluate the pavement response in exceptional condition, the dynamic parameters of a "hard" landing, were considered [18]. 


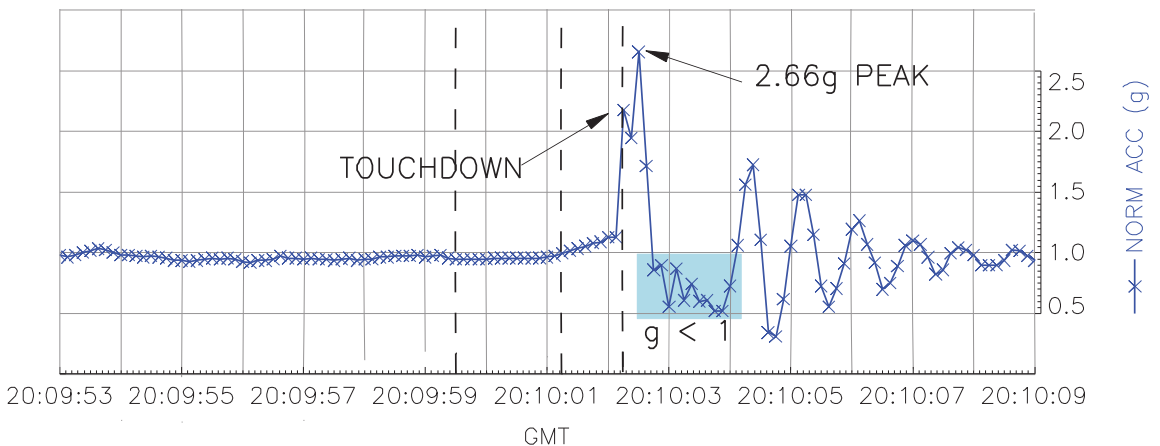

Fig. 1. Normal acceleration during landing phase [18].

Starting from that relation, the aircraft of mass $m$ (ignoring gear mass) is considered with the main gear shock absorbers represented by a linear model of total damping $C_{M}$ and stiffness $\mathrm{K}_{\mathrm{M}}$. Thus a single DoF model is proposed, where any fore-and-aft offset of the main gear from the aircraft centre of mass, and consequent pitch motion, are ignored. The equation for the aircraft as the gear comes into contact with the ground as shown in Figure 2 is then:

$$
m \ddot{z}_{M}+C_{M} \dot{z}_{M}+K_{M} z_{M}=L-m g=0
$$

where $\mathrm{z}_{\mathrm{M}}$ is measured from the aircraft position with the leg uncompressed. The weight $m g$ is included as a steady force because the final solution (once wing lift $\mathrm{L}$ has reduced to zero) must show a steady leg deformation equal to the sag of the aircraft on its landing gear. However, with lift $L$ present for the initial landing impact, sag will not occur since lift offsets the weight; the weight will only transfer on to the gear once the lift is 'dumped'.

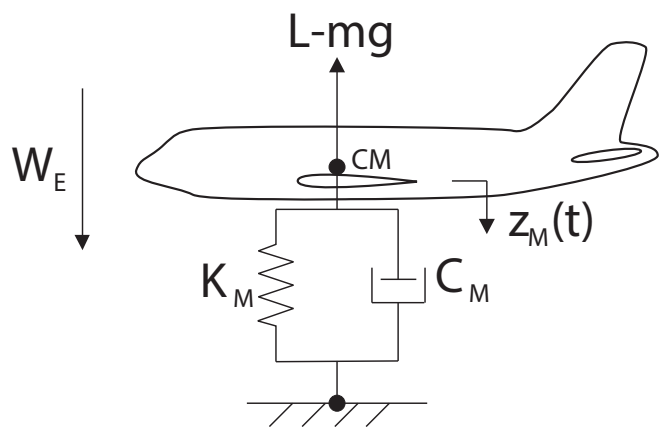

Fig. 2. Aircraft landing gear model [19]. 
At the moment the gear comes into contact with the ground, the aircraft is descending at a velocity $\mathrm{W}_{\mathrm{E}}$ (vertical landing velocity); note that the aircraft is also moving forward but this effect is ignored when using such a simple model to show the energy dissipation in the vertical direction. The initial conditions at the moment of impact are then $\mathrm{z}_{\mathrm{M}}(0)=0, \dot{\mathrm{z}}_{\mathrm{M}}(0)=\mathrm{W}_{\mathrm{E}}$, which leads to free vibration of the aircraft on its gear Wright, Cooper [19].

From Eq. (2.2) it is possible to calculate the acceleration graph during the hard landing (Figure 3). As shown in Figure 3 the peak deceleration value, during the hard landing, is $1.99 \mathrm{~g} \mathrm{~m} / \mathrm{s}^{2}$. This value was used in the finite element model to calculate the maximum load of the main gear wheel. Under this load the contact area becomes:

$$
A_{c}=\frac{397025}{1.36}=291930\left(\mathrm{~mm}^{2}\right)
$$

Form (2.3) the footprint dimensions are: $L=646 \mathrm{~mm}$ and $L^{\prime}=452 \mathrm{~mm}$.

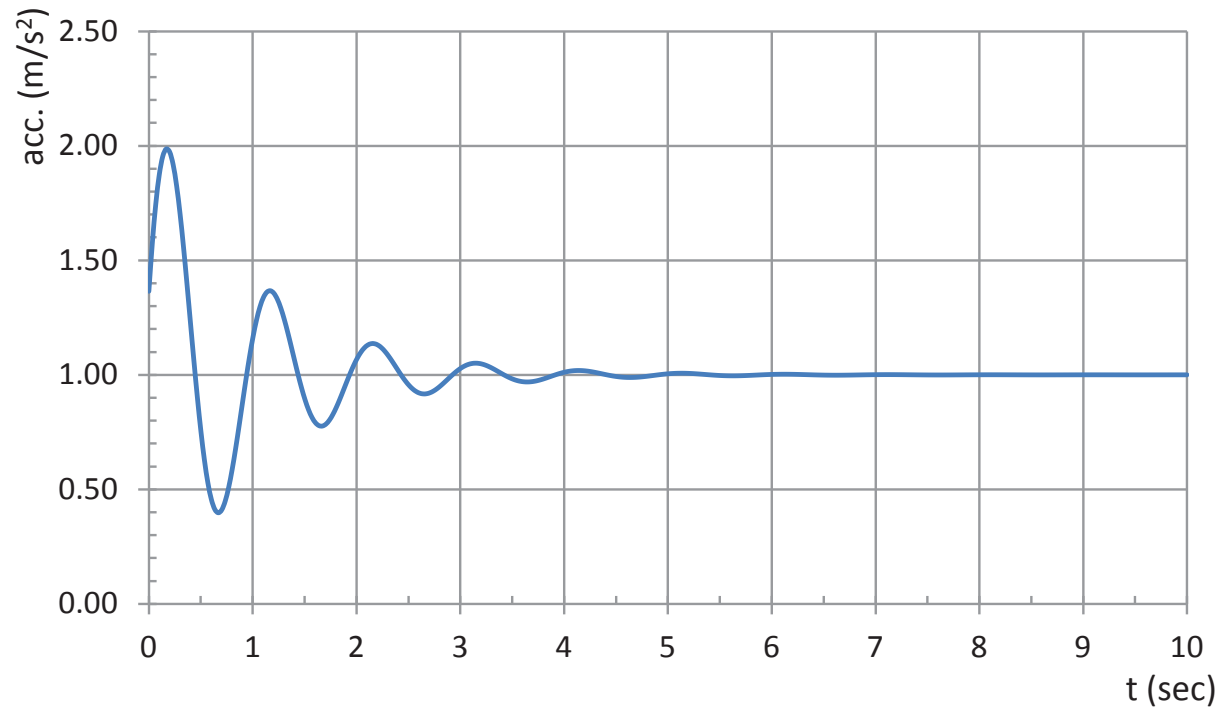

Fig. 3. Acceleration graph.

2.3 Materials PROPRIETIES

The pavement configuration is shown in Figure 4 and the material properties of pavement layers are given in Table 2. 
Elastic properties (modulus of elasticity and Poisson's ratio) are obtained by conducting laboratory testing on HMA materials and field non-destructive evaluation of granular and subgrade materials Buonsanti, Leonardi [20], Buonsanti et al. [21].

Table 2.

Properties of the layers thickness and elastic material.

\begin{tabular}{|c|c|c|c|}
\hline Layer & $\begin{array}{c}\text { Thickness } \\
(\mathrm{mm})\end{array}$ & $\begin{array}{c}\text { Modulus of elasticity } \\
(\mathrm{MPa})\end{array}$ & Poisson's ratio \\
\hline Surface & 100 & 7000 & 0.30 \\
\hline Base & 150 & 2000 & 0.35 \\
\hline Subbase & 210 & 400 & 0.35 \\
\hline Subgrade & infinite & 70 & 0.33 \\
\hline
\end{tabular}

For simplicity, the material proprieties of the granular layers and the base course were assumed to be time-independent and linear elastic.

Because recently the most common cause of rutting is associated with the HMA layer, especially on pavements with heavy loads Abed, Al-Azzawi [22], a time hardening creep model was incorporated to simulate the viscoelastic behaviour of the HMA surface layer Al-Quadi et al. [5]:

$$
\varepsilon^{c}=\mathrm{F}(\sigma, T, t)
$$

Creep strain $\left(\varepsilon^{c}\right)$ is a function of stress $(\sigma)$, time $(t)$ and temperature $(T)$.

Eq. (2.4) is only valid for constant stress and temperature. Kraus [23] explains the Bailey-Norton law which is capable of modelling primary and secondary creep. The formulation is derived on a basic assumption that material depends on the present stress state explicitly. In this approach, strain rate is represented by:

$$
\dot{\varepsilon}^{c}=\frac{\partial \varepsilon^{c}}{\partial t}=A \sigma^{n} t^{m}
$$

where:

$\varepsilon=$ Uniaxial equivalent creep strain rate,

$\sigma=$ Uniaxial equivalent deviatoric stress (Misses equivalent stress),

$t=$ total time,

$A, n, m=$ user defined constants functions of temperature.

$A$ and $n$ must be positive with $-1<m \leq 0$.

In this research, the temperature was assumed to be constant $\left(20^{\circ} \mathrm{C}\right)$ and the $m$ value was set at -0.5 while $n$ value is 0.67 and $A$ is $1.0 \mathrm{e}-9$. 


\subsection{FinIte ELEMENT MODEL}

The considered pavement section has the following dimensions: $5 \mathrm{~m}$ in $\mathrm{x}$ and $\mathrm{y}$ directions and $3.5 \mathrm{~m}$ in the $\mathrm{z}$ - direction. Figure 4 presents a sketch of the pavement structure geometry with the model characteristics.

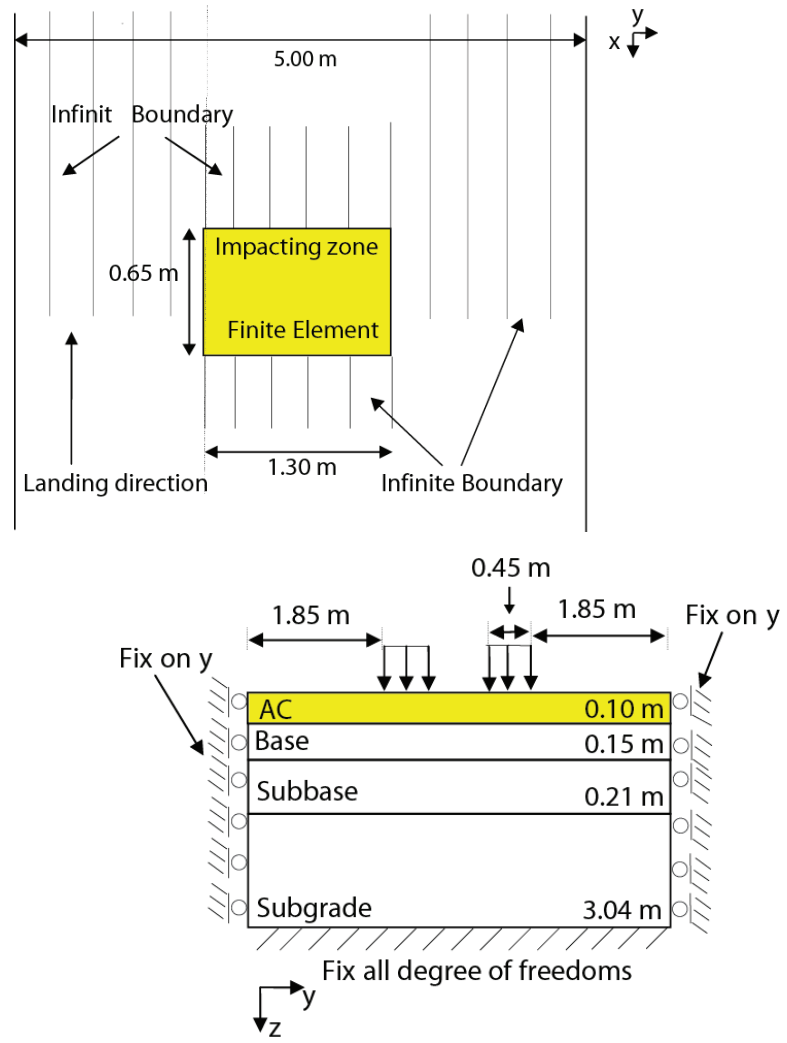

Fig. 4. Sketch of the simulated pavement structure.

The load of two main gear wheels during the landing phase was assumed to be symmetrically applied on the pavement surface. Since the boundary conditions have a significant influence in predicting the response of the model, the model was constrained at the bottom $(\mathrm{U} 1=\mathrm{U} 2=\mathrm{U} 3=\mathrm{UR} 1=\mathrm{UR} 2=\mathrm{UR} 3=0) ; \mathrm{X}-\operatorname{Symm}(\mathrm{U} 1=\mathrm{UR} 2=\mathrm{UR} 3=0)$ on the sides parallel to y-axis; and Y-Symm $(\mathrm{U} 2=\mathrm{UR} 1=\mathrm{UR} 3=0)$ on the sides parallel to $\mathrm{x}$-axis. All layers were-considered perfectly bonded to one another so that the nodes at the interface of two layers had the same displacements in all three $(\mathrm{x}, \mathrm{y}, \mathrm{z})$ directions. Assuming perfect bond at the layer interfaces implies that there are will be no slippage at the interface. This assumption is more applicable to hot mix asphalt layers, since the possibility of slippage is greater at the sub-base/subgrade interface Yin et al. [14]. 
The degree of mesh refinement is the most important factor in estimating an accurate stress field in the pavement: the finest mesh is required near the loads to capture the stress and strain gradients. The mesh presented has 69090 nodes and 64124 elements (49200 infinite linear hexahedral elements of type CIN3D8 and 14924 linear hexahedral elements of type C3D8R). In the FE model the infinite element is used to represent the infinite boundary in the landing direction. The finite element mesh considered for the analysis is shown in Figure 5.

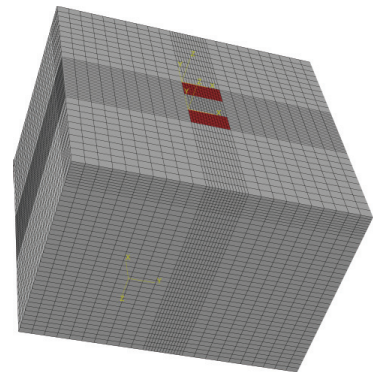

(a)

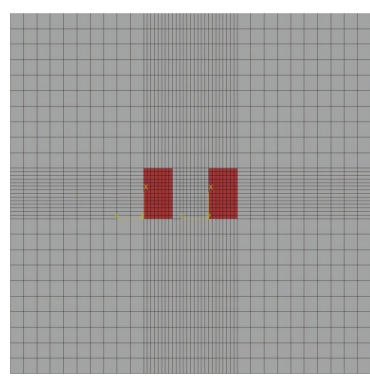

(b)

Fig. 5. Finite element model: (a) three-dimensional view; (b) plane view showing the area of applied load.

The loads were applied on the pavement surface with maximum pressure of 1060 $\mathrm{kPa}$ and distribution over the contact length Huang at al. [24] as illustrated in Figure 6.a. For simplicity, the dotted curve was used to represent the contact pressure distribution for each tire in the FE simulation.

Within each cycle, the load was applied with a duration time of $0.01 \mathrm{sec}$ in order to simulate the aircraft landing speed.

To analyse the behaviour of the pavement structure under repeated load cycles, in the simulation the load was removed for $1.0 \mathrm{sec}$ as shows in Figure 6.b.

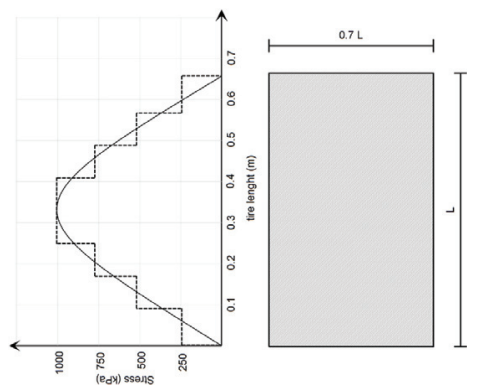

(a)

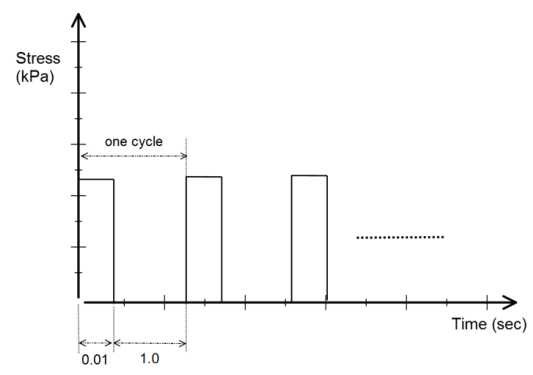

(b)

Fig. 6. Load pressure distribution over the tire contact (a) and schematic of applied cyclic load (b). 


\section{RESUlTS AND DISCUSSION}

The results of the simulation are illustrated in the following figures. The displacement is considered as a response of applying repeated loads. The final magnitude of the displacement $U$ beneath the centre of the load after 1000 cycles of loading is $0.39 \mathrm{~mm}$ (Figure 7.f).

A part of these displacements is recovered at the end of the load pulse, according to the resilient properties. The other part perpetuates. The permanent response is related to the plastic strains and represents the field rutting.

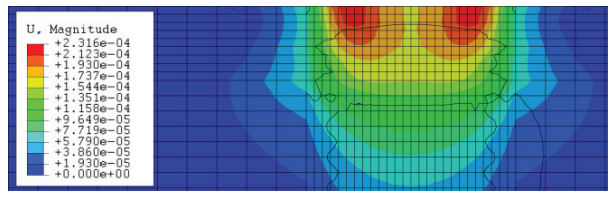

(a)

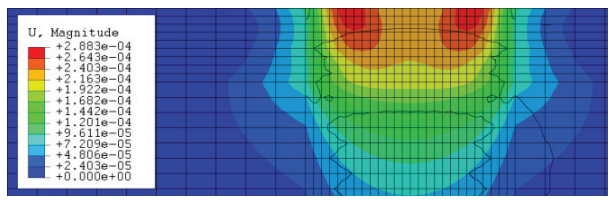

(c)

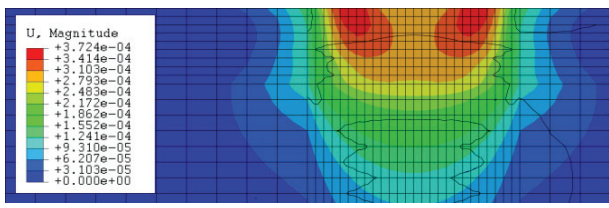

(e)

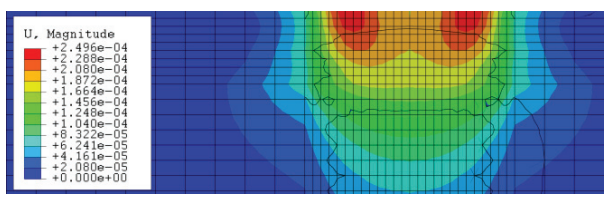

(b)

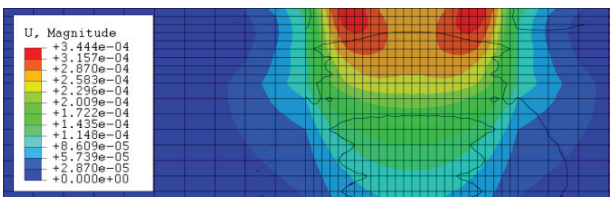

(d)

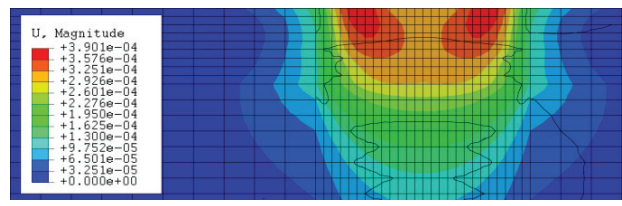

(f)

Fig. 7. Contours plot of the model displacement after (a) 50, (b) 100, (c) 250, (d) 500, (e) 750 and (f) 1000 cycles.

Figure 8 shows permanent deformation (rutting) across the transverse section under the center of loading for different cycles of load. The figure illustrates that the permanent deformation increases along with increasing the number of loading cycles. This result demonstrates that the model is able to capture the pavement behavior under repeated loads.

Figure 9 shows the relationship between rutting depth $(\mathrm{mm})$ and the number of load cycles $(\mathrm{N})$. This figure shows that the accumulation rate of rutting becomes smaller with an increase of loading cycles. Moreover, after $\mathrm{N}=500$, the asphalt material reaches the secondary creep stage. 


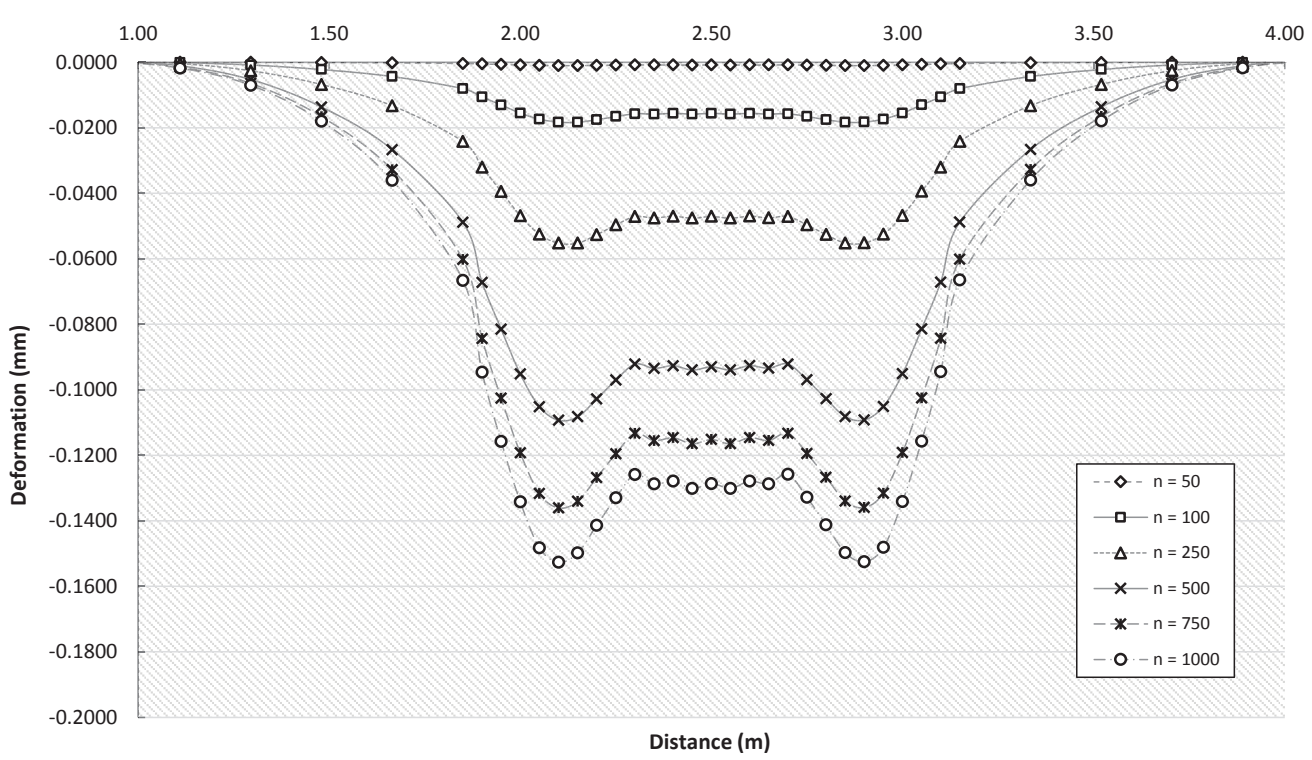

Fig. 8. Permanent deformation profile for different number of cycles.

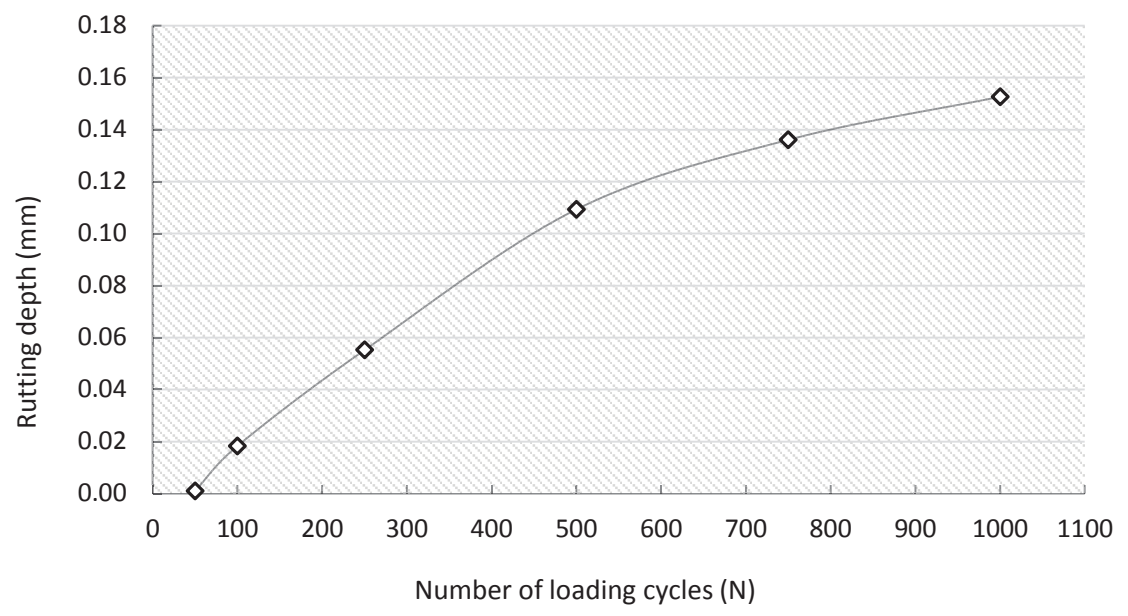

Fig. 9. Relationship between the number of cycles and the rutting depth. 


\section{Conclusions}

Finite element analysis of pavement structures, if validated, can be extremely useful, because it can be applied directly to estimate pavement response parameters without resorting to potentially costly field experiments.

If accurate correlations between the theoretically-calculated and the field-measured response parameters can be obtained, then the finite element model can be used to simulate pavement response utilizing measurements from strain gages. In particular, the proposed model has clearly confirmed the need and importance of 3-Dimensional finite element analyses on flexible pavements to consider the behaviour of the structure under high stress.

In particular, the importance of this research arises from the fact that several agencies adopted the rutting as failure criterion in pavement design. The simulation results from this study show that the proposed model has the capability to capture the pavement responses under repeated loads.

Future research advancements can be done in the direction of better profiling of the pavement behaviour under stress, in function of different combinations of variables as temperature, tire type and pressure.

\section{REFERENCES}

1. D. Johnson, B. Sukumaran, Y. Mehta, and M. Willis, "Three dimensional finite element analysis of flexible pavements to assess the effects of wander and wheel configuration," in FAA Worldwide Airport Technology Transfer Conference, Atlantic City, New Jersey, USA, 2007.

2. M. Buonsanti and G. Leonardi, "A Finite Element Model to Evaluate Airport Flexible Pavements Response under Impact," Applied Mechanics and Materials, vol. 138-139, pp. 257-262, 2011.

3. M. Buonsanti, G. Leonardi, and F. Scoppelliti, "Modelling Micro-Damage in Granular Solids," Key Engineering Materials, vol. 525-526, pp. 497-500, 2012.

4. M. Buonsanti, G. Leonardi, and F. Scopelliti, "A Unified Model for Micromechanics Damage in the Asphalt Concrete," Key Engineering Materials, vol. 578, pp. 465-468, 2014.

5. I. L. Al-QADI, M. Elseifi, and P. J. Yoo, "In-situ validation of mechanistic pavement finite element modeling," in 2nd International Conference on Accelerated Pavement Testing, Minneapolis, 2004.

6. S. Zaghloul and T. White, "Use of a three-dimensional, dynamic finite element program for analysis of flexible pavement," Transportation Research Record, pp. 60-60, 1993.

7. S. ZAGHLoul, "Non-linear dynamic analysis of flexible and rigid pavements," ETD Collection for Purdue University, 1993.

8. E. Taciroglu, "Constitutive modeling of the resilient response of granular solids," University of Illinois, 1995.

9. Y. Kim, Assessing pavement layer condition using deflection data: Transportation Research Board, National Research Council, 2001.

10. S. ERLingsson, "3-D FE analyses of HVS tested low volume road structures-comparison with measurements," 2002, pp. 2-5.

11. G. R. Chенав, Characterization of asphalt concrete in tension using a viscoelastoplastic model: North Carolina State University, 2002. 
12. S. Pirabarooban, M. Zaman, and R. Tarefder, "Evaluation of rutting potential in asphalt mixes using finite element modeling," in Annual Conference of the Transportation Association of Canada Transportation, St. John's, Newfoundland and Labrador, 2003, pp. 1-16.

13. M. A. Elseifi, I. L. Al-QAdi, and P. J. Yoo, "Viscoelastic modeling and field validation of flexible pavements," Journal of Engineering Mechanics, vol. 132, p. 172, 2006.

14. H. Yin, S. Stoffels, and M. Solaimanian, "Optimization of Asphalt Pavement Modeling based on the Global-Local 3D FEM Approach," Road materials and pavement design, vol. 9, pp. 345-355, 2008.

15. M. A. ONYANGO, "Verification of mechanistic prediction models for permanent deformation in asphalt mixes using accelerated pavement testing," 2009.

16. Y. Huang, Pavement analysis and design vol. 367: Prentice Hall, 1993.

17. AIRBUS, "Airplane Characteristics A321," 1995.

18. AAIB, “AAIB Bulletin: 6/2009 EW/C2008/07/02,” 2009.

19. J. Wright and J. COOPER, Introduction to aircraft aeroelasticity and loads: Wiley, 2007.

20. M. Buonsanti and G. Leonardi, "FEM Analysis of Airport Flexible Pavements Reinforced with Geogrids," Advanced Science Letters, vol. 13, pp. 392-395, 2012.

21. M. Buonsanti, G. Leonardi, and F. Scopelliti, "Theoretical and Computational Analysis of Airport Flexible Pavements Reinforced with Geogrids," in RILEM Bookseries. vol. 4, A. Scarpas, N. Kringos, I. L. Al-Qadi, and A. Loizos, Eds., ed: Springer 2012, pp. 1219-1227.

22. A. H. Abed and A. A. Al-Azzawi, "Evaluation of Rutting Depth in Flexible Pavements by Using Finite Element Analysis and Local Empirical Model," American Journal of Engineering and Applied Sciences, vol. 5, pp. 163-169, 2012.

23. H. Kraus, "Creep analysis," Research supported by the Welding Research Council. New York, WileyInterscience, 1980. 263 p, 1980.

24. C. Huang, R. Abu Al-Rub, E. Masad, and D. Little, "Three-Dimensional Simulations of Asphalt Pavement Permanent Deformation Using a Nonlinear Viscoelastic and Viscoplastic Model," Journal of Materials in Civil Engineering, vol. 23, pp. 56-68, 2011. 